\title{
Comprehensive dental evaluation of children with congenital or acquired heart disease-CORRIGENDUM
}

Kenan Cantekin, Isin Cantekin, Yasemin Torun

doi:10.1017/S1047951112001953, Published by Cambridge University Press, 20 November 2012.

First published online: 8 February 2013

The Authors listed above apologise for omitting Yucel Yilmaz from the author list.

The author list should read as follows:

Kenan Cantekin, ${ }^{\mathrm{a} 1, \mathrm{c} 1}$ Yucel Yilmaz, ${ }^{\mathrm{a} 2}$ Isin Cantekin ${ }^{\mathrm{a} 3}$ and Yasemin Altuner Torun ${ }^{\text {a }}$

${ }^{a 1}$ Department of Paediatric Dentistry, Faculty of Dentistry, University of Erciyes, Kayseri, Turkey

${ }^{\text {a2 }}$ Department of Paediatric Dentistry, Faculty of Dentistry, University of Ataturk, Erzurum, Turkey
${ }^{a 3}$ Department of Internal Medicine, Faculty of Health Sciences, University of Meliksah, Kayseri, Turkey

${ }^{a 4}$ Department of Pediatrics, Division of Pediatric Hematology, Kayseri Education and Research Hospital, Kayseri, Turkey

\section{Reference}

1. Kenan Cantekin, Isin Cantekin, Yasemin Torun. Comprehensive dental evaluation of children with congenital or acquired heart disease. Cardiol. Young. Published by Cambridge University Press, 20 November 2012. doi:10.1017/S1047951112001953. 